\title{
A VOZ DA MULHER EM TERRA NEGRA: FEMINISMO NEGRO E MERCADO EDITORIAL NA POESIA DE CRISTIANE SOBRAL
}

\section{THE BLACK'S WOMAN VOICE IN TERRA NEGRA: BLACK FEMINISM AND THE PUBLISHING MARKET IN CRISTIANE SOBRAL'S POETRY}

\author{
Anselmo Peres Alós ${ }^{1}$ \\ Jerfferson Paim Luquini ${ }^{2}$
}

DOI 10.116o6/issn.1981-7169.crioula.2018.150847

RESUMO: Este artigo tem como objetivo suscitar uma problematização em torno do feminismo negro e do mercado editorial a partir da poesia de Cristiane Sobral. Tomamos como foco da análise dois poemas, intitulados "Quem sabe em Aruanda” e "Deus é preta”, presentes no livro Terra Negra, publicado pela editora Malê no ano de 2017.

ABSTRACT: The purpose of this paper is to arouse a problematization regarding the black feminism and the publishing market set on Cristiane Sobral's poetry. We focus on the analysis of two poems: "Quem sabe em Aruanda" and "Deus é preta", presented in the book Terra Negra, published by publisher Malê in 2017.

PALAVRAS-CHAVE: Feminismo negro; Mercado editorial; Poesia.

\footnotetext{
1 Doutor em Letras pela UFRGS. Pós-Doutor pela UFPE. Professor do PPG-Letras da UFSM. Bolsista de Produtividade em Pesquisa (PQ-2) do CNPq.

2 Doutorando em Letras pelo PPG-Letras da Universidade Federal de Santa Maria (UFSM), sob a orientação do Prof. Dr. Anselmo Peres Alós. Bolsista CAPES/DS.
} 


\section{REVISTA CRIOULA N ${ }^{\circ} 22-2^{\circ}$ SEMESTRE/2018}

KEYWORDS: Black feminism; Publishing market; Poetry.

\section{Introdução}

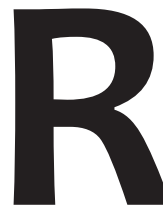

eferindo-nos ao histórico silenciamento e exclusão das escritoras negras da produção literária brasileira, buscamos problematizar esta

questão a partir da análise dois poemas da autora Cristiane Sobral. Deste modo, o objetivo é trazer um debate em torno do feminismo negro, identificando a partir das escuridões de Terra Negra (2017) o tipo de enfrentamento que a autora provoca.

Além disso, trazemos uma discussão a respeito do mercado editorial, para quem a mulher negra, na posição de autora, praticamente não existe, salvo algumas exceções. A poesia de Cristiane Sobral, além de fazer frente ao discurso racista e masculinista, traz à tona um passado histórico de opressão e de silenciamento. O leitor é convidado a cada verso a se desconstruir e se reinventar depois da experiência de leitura de Terra Negra.

Cristiane Sobral nasceu no Rio de Janeiro no ano de 1974, e atualmente vive em Brasília. Foi a primeira mulher negra a se formar em interpretação teatral pela UnB. Possui mestrado pela mesma instituição, com pesquisa sobre as estéticas nos teatros negros brasileiros. Além disso, ocupa a Cadeira 34 na Academia de Letras do Brasil (DF) desde 2014. Iniciou sua carreira como escritora em 2002, publicando nos Cadernos Negros.

Elisa Lucinda, no prefácio que abre o livro, nos diz que: “[...] a voz de uma mulher negra é a voz que se nega ao silenciamento, a voz que se impõe à porta da casa grande e entra. Arrebenta a tranca e ainda tem que provar, a cada balcão, o que é, quem é, e porque o é. Cansa até” (LUCINDA, 2017, p. 12, apud SOBRAL, 2017). É a partir deste lugar de fala, da negação ao silenciamento, que a autora mostra a força política de sua poesia. Entenda-se político aqui, no sentido atribuído por Terry Eagleton, quando o autor afirma que: 


\section{REVISTA CRIOULA N ${ }^{\circ} 22-2^{\circ}$ SEMESTRE/2018}

Por "político" entendo apenas a maneira pela qual organizamos conjuntamente nossa vida social, e as relações de poder que isso implica [...] qualquer teoria relacionada com a significação, valor, linguagem, sentimento e experiência humanos, inevitavelmente envolverá questões mais amplas e profundas sobre a natureza do ser e da sociedade humanos, problemas de poder e sexualidade, interpretações da história passada, versões do presente e esperanças para o futuro. (EAGLETON, 1983, p. 209-210)

O entendimento que Eagleton possui da palavra político nos remete diretamente para dentro da poesia de Sobral, uma vez que a mesma está circunscrita ao mundo captado pela autora de forma presente e consciente. $\mathrm{O}$ humano e todas as questões que o interpelam, como as relações de poder, sexualidade e religião, para citarmos alguns exemplos, são representados de forma crítica, de modo a desconstruir um lugar que na literatura foi marcado majoritariamente pela presença do homem branco, heterossexual e pertencente a uma elite econômica.

Dito isso na primeira parte deste trabalho, faremos a seguir uma breve incursão sobre o conceito de feminismo negro, sua história e seus desdobramentos. Na segunda parte, buscamos problematizar algumas questões referentes ao mercado editorial, tensões e dificuldades que as escritoras negras enfrentam para publicar seus livros. E, por último, debruçamo-nos na análise dos poemas "Quem sabe em Aruanda" e "Deus é preta”, mostrando o tipo de enfrentamento que a autora busca fazer através da sua poesia.

\section{No rastro do conceito: o que pode o feminismo negro?}

Começamos a problematizar o conceito de feminismo negro evocando um acontecimento ocorrido na convenção sobre direitos das mulheres em Akron, nos Estados Unidos da América, em 1851. Nesta ocasião, Sojourner 


\section{REVISTA CRIOULA N ${ }^{\circ} 22-2^{\circ}$ SEMESTRE/2018}

Truth, ex-escrava, estava engajada não somente no movimento pelo abolicionismo da escravatura, mas também pelos direitos das mulheres. Ela profere um discurso que acaba entrando para a história dos feminismos. Assim sendo, a primeira versão registrada foi feita por Marcus Robinson, na edição de 21 de junho de 1851 , que pode ser encontrada no site feminist.com. ${ }^{3}$

[...] neste sentido segue o discurso de Truth como ponto de partida para nossa discussão: [...] Nunca ninguém me ajuda a subir numa carruagem, a passar por cima da lama ou me cede o melhor lugar! E não sou uma mulher?

Olhem para mim! Olhem para meu braço! Eu capinei, eu plantei, juntei palha nos celeiros e homem nenhum conseguiu me superar! E não sou uma mulher?

Eu consegui trabalhar e comer tanto quanto um homem - quando tinha o que comer - e também aguentei as chicotadas! E não sou uma mulher? Pari cinco filhos e a maioria deles foi vendida como escravos. Quando manifestei minha dor de mãe, ninguém, a não ser Jesus, me ouviu! E não sou uma mulher? [...] Então aquele homenzinho vestido de preto diz que as mulheres não podem ter tantos direitos quanto os homens porque Cristo não era mulher! Mas de onde é que vem seu Cristo? De onde foi que Cristo veio? De Deus e de uma mulher! O homem não teve nada a ver com Ele. Se a primeira mulher que Deus criou foi suficientemente forte para, sozinha, virar o mundo de cabeça para baixo, então todas as mulheres, juntas, conseguirão mudar a situação e pôr novamente o mundo de cabeça para cima! E agora elas estão pedindo para fazer isto. É melhor que os homens não se metam. Obrigada por me ouvir e agora a velha Sojourner não tem muito mais coisas para dizer.

Este discurso é uma referência importante para pensarmos a constru ção social do gênero presente na ideia de mulher, iniciando também, segundo

\footnotetext{
3 TRUTH, Sojourner. Ain't I a Woman? Disponível em: <http://www.feminist.com/resources/artspeech/genwom/sojour.htm>. Acesso em: 30 jun. 2018.
} 


\section{REVISTA CRIOULA N ${ }^{\circ} 22-2^{\circ}$ SEMESTRE/2018}

J. M. Oliveira, “[...] um percurso para chegar nos anos 1980 do século XX e implodir esse edifício conceitual a que chamamos mulheres, desintegrador de todas as diferenças" (OLIVEIRA, 2017, p. 36). O discurso traz ainda um grande dilema que o feminismo hegemônico viria a enfrentar: a universalização da categoria mulher. Para Djamila Ribeiro (2017), outra questão que está imbricada neste contexto diz respeito a:

Esse debate de se perceber as várias possibilidades de ser mulher, ou seja, do feminismo abdicar da estrutura universal ao se falar de mulheres e levar em conta as outras intersecções, como raça, orientação sexual, identidade de gênero, foi atribuído mais fortemente à terceira onda do feminismo, sendo Judith Butler um dos grandes nomes. (RIBEIRO, 2017, p. 21)

Neste sentido, torna-se importante pensarmos o feminismo negro levando em consideração as intersecções, uma vez que as demandas das mulheres brancas nunca serão as mesmas da mulher negra. O termo interseccionalidade, cunhado em 1989 por Kimberlé Crenshaw em sua tese de doutorado, diz respeito a:

uma conceituação do problema que busca capturar as conseqüências estruturais e dinâmicas da interação entre dois ou mais eixos da subordinação. Ela trata especificamente da forma pela qual o racismo, o patriarcalismo, a opressão de classe e outros sistemas discriminatórios criam desigualdades básicas que estruturam as posições relativas de mulheres, raças, etnias, classes e outras. (CRENSHAW, 2002, p. 177)

A interseccionalidade seria um "dispositivo" que nos faz perceber que não pode haver primazia de uma opressão sobre outra. Sendo estas estruturantes, a ideia é romper com a estrutura. Raça, classe e gênero, são categorias 


\section{REVISTA CRIOULA N ${ }^{\circ} 22-2^{\circ}$ SEMESTRE $/ 2018$}

que não podem ser pensadas de forma isolada, mas sim de forma imbricada.

Todo processo de opressão e exclusão da mulher negra está permeado por elementos do racismo, machismo e preconceito de classe, colocando-as na condição de exploradas, tanto no mundo do trabalho como na esfera da sexualidade. Como nos lembra Silva (2013, p. 109),

As discriminações de raça e gênero produzem efeitos imbricados, ainda que diversos, promovendo experiências distintas na condição de classe e, no caso, na vivência da pobreza, a influenciar seus preditores e, consequentemente, suas estratégias de superação. Neste sentido, são as mulheres negras que vivenciam estas duas experiências, aquelas sempre identificadas como ocupantes permanentes da base da hierarquia social.

O feminismo negro norte-americano surgiu a partir de teóricas feministas militantes afrodescendentes, como Patricia Hill Collins, Bell Hooks, Kimberle Crenshaw e Audre Lorde. Elas procuraram pontuar o fato de que o feminismo tradicional não conseguia abarcar as necessidades e anseios das mulheres negras. De um outro lado, as mulheres negras apontavam a interseccionalidade como uma saída para melhor compreender os entrelaçamentos entre as diversas identidades, seja de gênero, raça, classe e orientação sexual. Diante deste cenário, Angela Davis, outra autora importante, nos diz que:

Raça é a maneira como a classe é vivida. Da mesma forma que gênero é a maneira como a classe é vivida. A gente precisa refletir bastante para perceber que entre essas categorias existem relações que são mútuas e outras que são cruzadas. Ninguém pode assumir a primazia de uma categoria sobre as outras. (DAVIS, 1997, p. 8)

A partir desta citação, a ativista política Angela Davis chama-nos a 


\title{
REVISTA CRIOULA N ${ }^{\circ} 22-2^{\circ}$ SEMESTRE $/ 2018$
}

atenção para o entrelaçamento entre as identidades, como elas se cruzam e não se excluem. É preciso dizer que durante séculos foi negado às mulheres negras a oportunidade de falar sobre suas experiências e sua forma de se colocar no mundo. Nesse sentido, destacamos as observações de Liv Sovik (2009) ao falar sobre o racismo. Para a autora, “[...] no debate sobre racismo brasileiro, reitera-se que a diferença racial não tem fundamento biológico. Mas a existência desse fundamento, mesmo fantasioso, está tão presente na sociedade que sua falta de embasamento científico acaba sendo irrelevante”. De acordo com Lia Vainer Shucman (2012), ainda, “[...] a branquitude é uma construção sociohistórica produzida pela ideia falaciosa de superioridade racial branca". A teoria feminista negra torna-se uma ferramenta essencial para compreendermos como as relações de poder constroem os sujeitos marcados pelas diferenças de gênero, raça, classe, sexualidades, idade e outras. Sabe-se que existem múltiplas correntes de feminismos, porém nosso foco aqui foi pensar o feminismo negro. Diante disso, para Sebastião (2010), o feminismo negro

\begin{abstract}
[...] seria um movimento político, intelectual e de construção teórica de mulheres negras que estão envolvidas no combate às desigualdades para promover uma mudança social de fato; não seriam mulheres preocupadas somente com as opressões que lhe atingem, mulheres negras estariam discutindo e disputando projetos. ${ }^{4}$ (p. 6)
\end{abstract}

Através desta definição da autora, é possível perceber que, muito mais do que um movimento que luta pelo combate às desigualdades, o feminismo negro

\footnotetext{
$4 \mathrm{O}$ fato é que, para Lélia Gonzalez, “[...] enquanto mulher negra sentimos a necessidade de aprofundar a reflexão, ao invés de continuarmos na repetição e reprodução de modelos que nos eram oferecidos pelo esforço de investigação das ciências sociais. Os textos só falavam da mulher negra numa perspectiva sócio-econômica que elucidava uma série de problemas propostos pelas relações raciais. Mas ficava (e ficará) sempre um resto que desafiava as explicações" (GONZALEZ, 1984, p. 225).
} 


\section{REVISTA CRIOULA N ${ }^{\circ} 22-2^{\circ}$ SEMESTRE/2018}

em sua concepção se estabelece como um campo político e intelectual a partir das mulheres negras. Dito isso, a questão aqui se centra no fato de que ao partir dessa visão universalista [branca e ocidental] de mulher, as feministas de primeira e segunda onda não levavam em consideração a identidade da mulher negra, a qual possuía uma construção social, cultural e histórica diferente do que se designa por "mulher" neste contexto universal. Deste modo, é preciso ficar claro que esse "universal" não levava em conta questões referentes à etnia e à classe, e o que fazia na verdade era combater uma visão "hegemônica" do que é ser mulher, visão essa que não acolhia as mulheres negras.

Todas essas questões aqui abordadas em torno do conceito de feminismo negro são importantes para o tipo de problema que estamos colocando em torno da poesia de Cristiane Sobral, tendo em vista que a sua poesia insere-se de forma dialógica neste arcabouço teórico e político, o qual tem como propósito levar em consideração todas as nuances que estão em torno da mulher negra e seu lugar no mundo.

\section{Mercado editorial: uma arena de tensões, possibilidades e enfrentamen- tos}

Falar da poesia de Cristiane Sobral em um contexto em que o mercado editorial está voltado para as grandes edições - seja de romance ou de best-sellers, os quais ganham destaque nas livrarias - coloca-nos no compromisso de pensar e problematizar este lugar, tendo como objetivo específico mostrar as tensões que as escritoras negras enfrentam para publicar seus livros.

Aqui é preciso colocar que as relações entre mercado e literatura têm sido ao longo da história muito diversas, pois, segundo Leone, "[...] quer vistas a partir da sua suposta negação no recurso a mecenas, da profissionalização do escritor ou das relações com a mídia" (VANOLI, 2010, apud LEONE 2014, p. 65). A autora ainda problematiza o fato de que o trabalho editorial 


\section{REVISTA CRIOULA N ${ }^{\circ} 22-2^{\circ}$ SEMESTRE/2018}

tradicionalmente combina critérios econômicos, políticos e estéticos nas suas diferentes fases, tais como a seleção de autores, de textos, editoração, impressão, modos de venda e de circulação.

Neste contexto, a proposta da editora Malê, a qual configura-se como sendo de pequeno porte, é de atuar de forma independente no mercado editorial. A editora abrange autores brasileiros, africanos e da diáspora. Já no que se refere ao gênero, traz publicações de conto, poesia, romance, crônica, ensaio e crítica textual. Além disso, promove o prêmio Malê de literatura, do qual jovens escritores negros podem participar através de seus textos. Embora a editora seja nova no mercado se comparada às demais, é possível identificar que sua proposta está justamente em lutar por uma maior visibilidade e respeito à autoria negra, além de buscar, desse modo, uma maior diversidade no mercado editorial.

Para tanto, no sentido de mostrar também as dificuldades que a própria escritora Cristiane Sobral enfrentou diante do mercado editorial, trazemos um trecho de sua fala, concedida através de uma entrevista via e-mail, na qual ela ratifica as dificuldades que a mulher/escritora negra enfrenta para publicar suas obras. Sobre a questão do mercado editorial em um contexto mais amplo a escritora explica:

Esse ano comemoro 18 anos publicando, mas levei mais de 10 anos para publicar a minha primeira obra. Na época, mandei para várias editoras, algumas me respondiam, dizendo gostar da minha escrita e sugerindo mudanças no texto, pediam que tirasse as discussões sobre o racismo e negritude e os pontos em defesa da mulher. Eu não aceitei, entendia que ceder seria retirar a essência da minha obra. Por outro lado, o fato de conhecer pouquíssimas mulheres negras escrevendo também revelava a dificuldade de adentrar o mercado editorial. (SOBRAL, 2018, entrevista concedida via e-mail) 


\section{REVISTA CRIOULA N ${ }^{\circ} 22-2^{\circ}$ SEMESTRE/2018}

Diante de sua fala, pode-se perceber que de fato a questão é permeada por embates que em muitos momentos desqualificam os textos das escritoras negras, cuja força poética está justamente nas palavras redigidas em cada verso, no sentido de libertação, de poder dizer aquilo que por muito tempo ficou silenciado. Nesse contexto, é interessante perceber as questões sociais, culturais e políticas que são mobilizadas para dentro dos textos, tendo em vista que nenhum texto, seja ele literário ou não, foge ao contexto sociocultural em que se situa. Nesse sentido, a autora continua:

A literatura parecia um ambiente destinado aos ricos, homens e brancos. Uma publicação independente também custava alto e sofria o preconceito de mercado. Eu tentei muito e dez anos depois acabei publicando de forma independente. Em seis meses vendemos 1000 livros, ali recebi o retorno dos leitores dizendo: não pare de escrever, mas continuei com muitas dificuldades, muito cansada, publicando de forma independente em todos os outros livros. Todos com ótimos resultados de venda, considerando a estrutura mínima da qual disponho. Tenho 6 livros publicados. Somente O Tapete voador (contos) e Terra Negra (poesia), saíram pela editora Malê. (SOBRAL, 2018, entrevista concedida via e-mail)

Nota-se que a própria autora, depois de muito tempo, conseguiu publicar seu livro de forma independente. Esta questão torna-se pertinente ao revelar outra nuance que merece ser problematizada no contexto do mercado editorial contemporâneo. Referimo-nos aqui ao gerenciamento que o escritor ou artista passa a ter de si mesmo e de sua obra. De acordo com Milena Britto (2017, p. 70), “[...] o escritor tem de pensar a si mesmo como um gestor; que tem de transformar a sua criação em um projeto com características financeiras, estéticas, sociais e políticas”.

Essa questão levantada pela autora refere-se ao autor contemporâneo, 


\section{REVISTA CRIOULA N ${ }^{\circ} 22-2^{\circ}$ SEMESTRE $/ 2018$}

mostrando de certa forma uma mudança no modo de encarar a produção literária. O autor não é mais apenas o agente da produção, o criador, ele passou a ter outra demanda que é justamente se "autopromover", contexto no qual as redes sociais e a Internet adquirem uma importância significativa.

Por outro lado, ainda no que diz respeito à dificuldade que as escritoras negras encontram para publicar seus textos, não podemos desconsiderar o cenário político que está colocado. E tal afirmação justifica-se levando em consideração o que Cristiane Sobral nos diz, tendo em vista o lugar da mulher negra para o mercado editorial:

A mulher negra escritora ainda não existe para o mercado editorial, e as exceções só confirmam a regra. É mais fácil publicar uma autora negra estrangeira, isso dá glamour, mas falar sobre a realidade da mulher negra a partir da sua subjetividade, a quem interessa? Será que o Brasil está disposto a ouvir? Será que os poderosos do país querem revelar esse aspecto da nossa opressão e exclusão? (SOBRAL, 2018, entrevista concedida via e-mail)

A fala marca o lugar da opressão e da exclusão que as escritoras negras ainda enfrentam diante do mercado editorial. Mas, para, além disso, percebe-se que o problema atinge um âmbito muito maior e está diretamente relacionado com a questão política. A quem interessa o que escritoras negras têm a dizer? Quem está disposto a ouvir uma subjetividade negra? E mais: parece que ocorre um silenciamento de um passado que foi marcado pela opressão e exclusão, do qual ninguém está interessado em falar ou problematizar.

É preciso entender o caráter ético-político que está em volta da questão, tendo em vista que estamos problematizando ações humanas que perpassam sua existência e seu modo de (re)existir, caracterizando aqui um princípio ético. E ele é político, porque está imerso em um discurso que é datado historicamente, buscando através da subjetividade negra mostrar as tensões e 


\section{REVISTA CRIOULA N ${ }^{\circ} 22-2^{\circ}$ SEMESTRE/2018}

contradições que atingem diretamente a mulher negra.

Portanto, torna-se urgente e necessário resgatar essas vozes que foram e ainda são, em muitos contextos, silenciadas, mostrando uma produção que na verdade sempre existiu no que diz respeito à literatura afro-brasileira, e especificamente a escrita de mulheres negras. Na próxima sessão do artigo, mostraremos a partir dos poemas como a voz da mulher negra aparece na poesia de Cristiane Sobral.

\section{A voz da mulher negra em "Quem sabe em Aruanda" e "Deus é preta”}

Todos os caminhos percorridos até aqui foram importantes para que pudéssemos ter um maior entendimento das questões que estão presentes na poesia de Cristiane Sobral. Tais questões, que dizem respeito ao erotismo, ao gênero e ao mundo dos orixás revela a voz de uma mulher negra, que nos convida a uma conversa histórica, sincera, lírica e corajosa.

Essa voz nos mostra um passado de exclusão e de silenciamento, e busca também um novo modo de reexistir diante de um mundo marcado pelas desigualdades sociais, pela imposição capitalista e pelo desrespeito ao culto dos orixás. Sua poesia, para além de expressar uma resistência e uma luta de combate a todo tipo de preconceito, proporciona uma desconstrução salutar e necessária. Essa “desconstrução" que estamos mencionando está atrelada ao fato de a autora trazer em sua poesia questões que ainda são caras em nossa sociedade, como é o caso do machismo, do racismo e das questões de gênero.

Para tanto, a poesia de Cristiane Sobral deve ser entendida como poesia de anunciação, tendo em vista que o termo "resistir" configura-se em paralisar, ficar imóvel, sem conseguir sair do lugar. Todavia, o que percebemos diante dos poemas é uma caminhada que resgata um passado histórico, considerando que esse resgate histórico é feito no sentido de que não podemos esquecer o quanto a mulher negra foi subalternizada e silenciada diante 


\section{REVISTA CRIOULA N ${ }^{\circ} 22-2^{\circ}$ SEMESTRE/2018}

de uma sociedade hegemônica e opressora. Deste modo, o termo anunciação ganha uma conotação que enriquece, em nossa interpretação, a proposta da autora, que é justamente a de expor e reivindicar a sua subjetividade negra, partindo de suas experiências. Essa voz, que anuncia, fala da sua religião sem medo, como fica expresso em "Quem sabe em Aruanda".

Eu hoje só queria sentar na calçada e sorrir

Não lembrar que todos os dias eu preciso

Proteger meu corpo preto para existir

Quem sabe deitar debaixo de uma árvore, até dormir

Esquecer que ainda é necessário correr

Porque muitos sempre estiveram à minha frente

Porque sou mulher preta

Porque nunca mamei na teta de um Estado ausente

Eu hoje só queria estar com os meus

Não ter que explicar o meu Deus

Só queria não ter que afirmar quem eu sou e viver em paz.

(SOBRAL, 2017, p. 68)

Na primeira estrofe, fica evidente a vontade do eu-lírico em estar bem, "sentar" e "sorrir" sem precisar proteger seu corpo preto. Aqui é preciso lembrar, e mais do que isso, é urgente nomear a realidade, no que diz respeito a “proteger seu corpo preto”. Como nos ensina Djamila Ribeiro, “[...] se não se nomeia uma realidade, sequer serão pensadas melhorias para uma realidade que segue invisível $^{6}$ " (RIBEIRO, 2017, p. 41). Além disso, a autora nos alerta em relação ao alarmante quadro da violência em relação às mulheres negras:

5 Aruanda é o nome dado a um lugar específico no plano espiritual, local reservado para espíritos trabalhadores da umbanda, que já alcançaram uma maior evolução e agora continuam trabalhando como intermediários entre o plano físico e espiritual em nome do bem e da caridade.

6 De acordo com o mapa da violência de 2015, houve um aumento de 54,8\% de assassinatos de mulheres negras, ao passo que o de mulheres brancas diminuiu em 9,6\%. (WAISELFISZ, Julio 2015) 


\section{REVISTA CRIOULA N ${ }^{\circ} 22-2^{\circ}$ SEMESTRE/2018}

Esse aumento alarmante nos mostra a falta de um olhar étnico-racial no momento de se pensar políticas de enfrentamento à violência contra as mulheres, já que essas políticas não estão alcançando as mulheres negras. $O$ "mulheres" aqui atingiu, majoritariamente, mulheres brancas. (RIBEIRO, 2017, p. 42)

Diante desta realidade, a equação é clara: há um genocídio da população negra, no qual homens e mulheres, para além de todas as questões de desigualdade e preconceito racial, precisam mais do que nunca lutar pela sobrevivência diária:

Esquecer que ainda é necessário correr

Porque muitos sempre estiveram à minha frente Porque sou mulher preta

Porque nunca mamei na teta de um Estado ausente. (SOBRAL, 2017, p. 68)

Percebe-se aqui que o eu-lírico está se referindo ao fato de ter que estar sempre em busca de melhores condições, seja no âmbito social ou no do trabalho. A desigualdade de salário, por exemplo, entre uma mulher branca e uma mulher negra ainda é alarmante. Outra questão que é preciso ser esclarecida refere-se ao fato de que as condições de uma mulher branca não são as mesmas da mulher negra. É preciso reconhecer que a mulher branca sempre esteve em um lugar de privilégio social.

Já na segunda estrofe do poema, a referência ao seu Deus vem à tona, mostrando ao leitor que esta voz que fala não nega suas origens africanas, ao contrário procura em Aruanda um alento para viver em paz:

Eu hoje só queria estar com os meus

Não ter que explicar o meu Deus Só queria não ter que afirmar quem eu sou e viver em paz. (SOBRAL, 2017, p. 68) 


\section{REVISTA CRIOULA N ${ }^{\circ} 22-2^{\circ}$ SEMESTRE/2018}

O primeiro verso desta segunda estrofe pode ser entendido como estar com os companheiros de religião ou de cor. "Não ter que explicar o meu Deus", (SOBRAL, 2017, p. 68); diz respeito ao fato de que, pela anunciação do termo "Aruanda" já no título do poema, este Deus refere-se à Umbanda, religião de matriz africana. E aqui é interessante perceber o porquê de a população negra ter que justificar o seu Deus, sendo que os cristãos não precisam explicar o seu Deus "Branco".

Neste contexto, ao falarmos da Umbanda, precisamos entender sua história e origem. Segundo Pinto (2014, p. 25), "tem seu registro de nascimento em 15 de novembro de 1908, no bairro das Neves, no município de São Gonçalo, no Estado do Rio de Janeiro”. Foi fundada por Zélio de Moraes, que na época tinha apenas dezessete anos de idade. Neste período, o médium encontrava-se acometido por uma enfermidade que não foi identificada pelos médicos, o que obrigou aos seus pais a procurar ajuda religiosa na esperança de salvar a vida do filho. Por outro lado, de acordo com a autora, “[...] diversos médiuns incorporaram espíritos de Pretos Velhos e Caboclos” (PINTO, 2014, p. 25); causando um espanto no dirigente do templo. Outro fato importante a ser mencionado diz respeito a:

Uma médium vidente, que estava presente na reunião, descreveu o espírito como um indígena. Ouvindo isso, o dirigente perguntou-lhe por que se apresentava daquela forma, e ficou curioso em saber seu nome. $O$ espírito respondeu-lhe que, se fosse preciso ter um nome, que o chamassem de caboclo das sete encruzilhadas. Além disso, anunciou que, no dia seguinte, ele fundaria uma religião, que a mesma deveria chamar-se Umbanda e seria baseada na prática do amor e da caridade. (PINTO, 2014, p. 26)

Esta passagem marca o momento histórico de nascimento da Umbanda, considerada uma religião genuinamente brasileira. Assim sendo, não po- 


\section{REVISTA CRIOULA N ${ }^{\circ} 22-2^{\circ}$ SEMESTRE/2018}

demos desconsiderar o fato de que existem controvérsias relacionadas a seu surgimento.

Já para Lísias Negrão (1996), a Umbanda começa com seu processo de institucionalização na década de 1920, quando “[...] kardecistas de classe média, atraídos pelos espíritos de caboclos e pretos-velhos, incorporavam em terreiros de macumba no Rio de Janeiro” (NEGRÃO, 1996, p. 113). Negrão traz um dado importante referente ao ano de 1941, quando foi realizado, no Rio de Janeiro, o Primeiro Congresso Nacional de Umbanda. Este nome foi adotado justamente para fugir da estigmatização do termo macumba.

Neste sentido, não podemos esquecer que a Umbanda foi em muitos momentos perseguida na época da Ditadura do Estado Novo, levando dirigentes e praticantes a serem presos por crime de charlatanismo e curandeirismo. No entanto, a partir do Censo de 1991 (PEREIRA, 2013), o IBGE (Instituto Brasileiro de Geografia e Estatística) incluiu a Umbanda na classificação das religiões, elaborada em parceria com o ISER (Instituto Superior de Estudos da Religião). Assim, o sacerdote de Umbanda foi equiparado às autoridades das demais religiões existentes no país, legitimando através disso toda uma prática e ritual que faz parta da cultura e da formação histórica da sociedade Brasileira.

Esses breves esclarecimentos em torno da Umbanda fazem-se necessários para termos uma melhor compreensão do que o eu-lírico do poema está expressando. Desse modo, o título do poema assume uma importância significativa, pois "Quem sabe em Aruanda" se possa viver em paz, e não se tenha de explicar o seu Deus, não se tenha de proteger seu "corpo preto", não se tenha de correr atrás porque muitos sempre estiveram na sua frente. Aruanda assume um lugar idílico, no qual todas as mazelas da sociedade seriam, por um breve momento, esquecidas.

Deus é preta 


\title{
REVISTA CRIOULA N ${ }^{\circ} 22-2^{\circ}$ SEMESTRE/2018
}

\author{
Deus é uma mulher preta \\ Sua teta sempre \\ matou a fome do mundo. \\ (SOBRAL, 2017, p. 70)
}

Neste poema de apenas uma estrofe, é possível perceber a coragem que a voz da mulher negra tem, a qual vem romper com os padrões estabelecidos por uma sociedade hipócrita e preconceituosa. Traz-se a partir deste poema uma inversão da questão de gênero, quando o "Deus" que é retratado pela autora aparece como sendo uma mulher preta. Fica evidente a desconstrução que se pretende provocar no leitor, tendo em vista que o Deus que todos nós conhecemos foi pintado pela sociedade como branco e de olhos azuis.

Contudo, é possível relacioná-lo ao discurso de Sojouner Truth, mobilizado para pensarmos o conceito de feminismo negro. A partir do discurso percebemos a questão de gênero sendo desconstruída por Truth:

Aquele homem ali diz que é preciso ajudar as mulheres a subir numa carruagem, é preciso carregar elas quando atravessam um lamaçal e elas devem ocupar sempre os melhores lugares. Nunca ninguém me ajuda a subir numa carruagem, a passar por cima da lama ou me cede o melhor lugar! E não sou uma mulher? Olhem para mim! Olhem para o meu braço! Eu capinei, eu plantei, juntei palha nos celeiros e homem nenhum conseguiu me superar! E não sou uma mulher? (TRUTH 1851 apud RIBEIRO, 2017, p. 20)

A fala mostra que os papéis de gênero atribuídos à mulher são colocados à prova, tendo em vista que Truth, sendo mulher, conseguia também realizar todas as tarefas que seriam destinadas aos homens. É preciso compreender que a discussão em torno do gênero não é recente, e o próprio discurso 


\section{REVISTA CRIOULA N ${ }^{\circ} 22-2^{\circ}$ SEMESTRE/2018}

aqui nos mostra que no século XIX ele já vinha sendo questionado. Além desta questão de suma importância, Truth, no mesmo discurso, traz um questionamento que se torna em nosso entendimento o ponto fulcral de diálogo com o poema de Cristiane Sobral. Diz ela: “[...] então aquele homenzinho vestido de preto diz que as mulheres não podem ter tantos direitos quanto os homens porque Cristo não era mulher!”. (TRUTH, 1851).

Essa passagem do discurso dialoga diretamente com o poema, quando Cristiane Sobral diz que "Deus é uma mulher preta" (SOBRAL, 2017, p. 70); Se as mulheres não podem ter tantos direitos quanto os homens, pelo fato de Deus não ser uma mulher, basta invertermos a equação e colocar esse "Deus" como sendo uma mulher, e mais, uma mulher preta. Podemos ainda perceber diante desta passagem do discurso que o nome de Deus é colocado em um primeiro plano para deslegitimar os direitos das mulheres, ou seja, colocá-las em um lugar de inferioridade em relação aos homens.

Para tanto, além de Cristiane Sobral nos proporcionar outro olhar para a questão, ela avança no sentido de que, além de desconstruir esse Deus homem e branco, nos diz que ele é uma mulher e "sua teta sempre matou a fome do mundo" (SOBRAL, 2017, p. 70). Nestes dois últimos versos do poema, é preciso lembrar-nos que, no decorrer da história, as amas de leite, mulheres negras, deixavam de alimentar suas crianças para alimentar os filhos de suas senhoras, quando as mesmas já não tinham mais leite. Diante disso, em nossa interpretação, é preciso lembrar que essa fome está atrelada também a todas as questões sociais e culturais que são restritas a população negra.

É uma fome que não está apenas relacionada ao ato de se alimentar, mas abrange questões muito mais amplas, como as lutas por igualdade de direitos, contra o feminicídio e contra o racismo. Percebe-se que estamos falando de uma fome pela própria sobrevivência em uma sociedade desigual, opressora e patriarcal.

A partir das análises, podemos dizer que tanto o feminismo negro 


\section{REVISTA CRIOULA N ${ }^{\circ} 22-2^{\circ}$ SEMESTRE/2018}

quanto a questão do mercado editorial, os quais mobilizamos para pensar a poesia de Cristiane Sobral, nos revelam uma situação que ainda precisa ser nomeada, os escritorxs negrxs, ainda continuam sendo minoria dentro do mercado editorial.

Percebemos que a questão do feminismo negro torna-se um grande aliado dessas autoras, seja para dizer e pensar-se a si mesmas ou para colocar-se no mundo, de forma a reivindicar um espaço de (re) existência, proporcionando múltiplos modos de se fazer visível.

\section{Considerações finais}

Este trabalho foi um passo importante para pensarmos o silenciamento e a exclusão que as escritoras negras sofreram [e ainda sofrem em diversos contextos] no que se refere à produção literária brasileira. Além disso, olhar para o contexto do mercado editorial tornou-se necessário justamente para pensar este cenário e mostrar as dificuldades que tais escritoras enfrentam para publicar seus livros. Como coloca a própria autora Cristiane Sobral, “[...] a mulher negra praticamente não existe para o mercado editorial”. (SOBRAL, 2018, entrevista concedida via e-mail).

Assim sendo, considerando os limites deste trabalho, nossa proposta foi a de trazer uma discussão em torno do feminismo negro, na intenção de mostrar o quanto a poesia de Cristiane Sobral dialoga com este campo epistemológico de conhecimento. Além disso, é interessante perceber que sua poesia está marcada por um contexto que leva em consideração não só a questão da mulher negra, bem como o seu passado histórico de silenciamento e exclusão, além de refletir acontecimentos do âmbito social, cultural e político, presentes em nossa sociedade.

Nesse sentido, para além da questão da resistência, falamos aqui de uma poesia que faz uma denúncia à opressão da mulher negra, proporcionan- 


\section{REVISTA CRIOULA N ${ }^{\circ} 22-2^{\circ}$ SEMESTRE/2018}

do um convite à desconstrução e a forma de encarar tais questões tão caras em nossa sociedade machista, opressora e patriarcal. Para tanto, as teorias feministas e, sobretudo, o feminismo negro, tornam-se grandes aliados, proporcionando-nos um olhar amplo e menos ingênuo no que se refere ao lugar que a mulher negra ocupa na sociedade.

Corroborando com essa questão, Djamila Ribeiro, em seu livro O que é lugar de fala? diz-nos que "[...] a questão tanto das histórias de resistências e produções de mulheres negras, e consequentemente com a produção e atuação de feministas negras, é que esse debate já vinha sendo feito; o problema, então, seria a sua falta de visibilidade" (RIBEIRO, 2017, p. 21). Por outro lado, no que se refere aos dois poemas que escolhemos para analisar, podemos perceber que ambos tratam de uma mesma temática: a religião, a qual vem atrelada a outras questões que dizem respeito à corporeidade e à subjetividade negra. Por fim, a poesia de Cristiane Sobral deve ser encarada com uma poesia de enfrentamento às diversas questões que a sociedade busca a todo instante negar à população negra, sobretudo no que diz respeito ao lugar da mulher negra perante aos espaços que durante muito tempo foram majoritariamente ocupados por homens brancos.

\section{REFERÊNCIAS BIBLIOGRÁFICAS}

BRITTO, Milena. Afetar a cena literária: política, afinidade, estratégias e autogestão entre os autores contemporâneos". In: Palavras da crítica contemporânea. AZEVEDO, Luciane; PEREIRA, Antonio Marcos (Orgs.). Salvador: Boto-cor-de-rosa, 2017.

CARMO, Isabel; AMÂNCIO, Lígia. Vozes insubmissas. Lisboa: D. Quixote, 2004. CRENSHAW, Kimberlè. "Documento para o encontro de especialistas em aspectos da discriminação racial relativos ao gênero". Revista de Estudos Femi- 


\section{REVISTA CRIOULA N ${ }^{\circ} 22-2^{\circ}$ SEMESTRE/2018}

nistas, 2002, v. 7, n. 12, p. 171-88.

DAVIS, A. As Mulheres Negras na Construção de uma Nova Utopia. Disponível em: <arquivo.geledes.org.br/atlantico-negro/movimentoslideres-pensadores/afroamericanos/10243-as-mulheres-negras-naconstrucao-de-uma-nova-utopia-angela-davis $>$.

EAGLETON, Terry. Teoria da literatura: uma introdução. Trad. Waltensir Dutra. São Paulo: Martins Fontes, 1983.

GONZALEZ, Lélia. Racismo e sexismo na cultura brasileira. Revista Ciências Sociais Hoje, São Paulo: ANPOCS, 1984, p. 223-244. Disponível em: <https:// pt.scribd.com/document/105552855/Racismo-e-Sexismo-Na-Cultura-Brasileira $>$. Acesso em: 6 jun. 2018.

LEONE, Luciana di. Poesia e escolhas afetivas: edição e escrita na poesia contemporânea. Rio de Janeiro: Rocco, 2014.

LUCINDA, Elisa. Vozes guardadas. Rio de Janeiro: Record, 2016. Rio de Janeiro: Record, 2014.

NEGRÃO, Lísias Nogueira. Entre a cruz e a encruzilhada: formação do campo umbandista em São Paulo. São Paulo: EDUSP, 1996.

NOGUEIRA, Conceição. Um novo olhar sobre as relações sociais de gênero. Lisboa: Gulbenkian, 2001.

OLIVEIRA, João Manuel de. Desobediências de gênero. Salvador: Devires, 2017. . A necropolítica e as sombras na teoria feminista. Ex æquo, n. 29, Lisboa: APEM, 2014, p. 69-82. Acesso em: 2 ago. 2018.

PINTO, Flávia. Umbanda religião brasileira: guia para leigos e iniciantes. Rio de Janeiro: Pallas, 2014.

PEREIRA, Nilza de Oliveira Martins. As religiões nos censos brasileiros, informações preliminares do Censo Demográfico 2000. $54^{\text {a }}$ Reunião Anual da SBPC. Goiás, 2002. Disponível em: <http://www.sbpcnet.org.br/eventos/54RA/ TEXTOS/SBPC/SBPC\%20....... . . Acesso em: 1 ago. 2018.

RIBEIRO, Djamila. O que é lugar de fala? Belo Horizonte: Letramento/Justifi- 


\section{REVISTA CRIOULA N ${ }^{\circ} 22-2^{\circ}$ SEMESTRE $/ 2018$}

cando, 2017.

SOBRAL, Cristiane. Terra Negra. Rio de Janeiro: Malê, 2017. . O tapete voador. Rio de Janeiro: Malê, 2016. . Entrevista concedida a Jerfferson Paim Luquini. E-mail, 9 mai. 2018.

SEBASTIÃO, Ana Angélica. Feminismo negro e suas práticas no campo da cultura. Revista da Associação Brasileira de Pesquisadores/as Negros/as ( $A B P N)$, v. 1, n. 1, Goiânia: ABPN, p. 64-77, jun. 2010. Disponível em: <http://abpnrevista.org.br/revista/index.php/revistaabpn1/article/view/308>. Acesso em: 7 jun. 2018.

SILVA, T. T. (org.). Identidade e Diferença: perspectiva dos estudos culturais. Petrópolis: Vozes, 2000.

SCHUCMAN, Lia Vainer. Entre o "encardido", o "branco" e o "branquíssimo": Raça, hierarquia e poder na construção da branquitude paulistana. Tese de Doutorado apresentada ao Instituto de Psicologia da Universidade de São Paulo, 2012.

SOVIK, Liv. Aqui ninguém é branco. Rio de Janeiro: Aeroplano, 2012.

WAISELFISZ, Julio Jacobo. Mapa da violência 2015: homicídio de mulheres no Brasil. Brasília: FLASCO Brasil. Disponível em: <https://www.mapadaviolencia.org.br/mapa2015_mulheres.php>. Acesso em: 7 jun. 2018.

Submissão: 04/10/2018

Aceite: 15/11/2018 